\title{
¡BIENVENIDO MR. MIKOYÁN!: \\ TACOS Y TRACTORES A LA SOMBRA DEL ACERCAMIENTO SOVIÉTICO-MEXICANO, 1958-1964
}

\author{
Vanni Pettinà \\ El Colegio de México
}

INTRODUCCIÓN

F n noviembre de 1959, Anastás Mikoyán, vicepresidenEte del Consejo de Ministros de la URSS y brazo derecho del premier Nikita Khrushchev, aterrizaba en la Ciudad de México para inaugurar una macroexposición de productos técnicos y científicos soviéticos. La agenda de la visita, además, preveía una serie de encuentros con los principales dirigentes políticos del país, incluyendo al propio presidente Adolfo López Mateos. La revista LIFE, en su cobertura fotográfica de la visita, presentaba, bajo el ingenioso título de "Mik's Mexican Mix" (El mix mexicano de Mik), a un Mikoyán bebiendo tequila y, posteriormente, ingiriendo de forma algo torpe unos tacos, en el intento de contrabalancear la fuerte carga alcohólica del licor a base de agave. Al fondo de las imágenes, se podía observar a unos atentos funcionarios

Fecha de recepción: 3 de diciembre de 2015

Fecha de aceptación: 23 de febrero de 2016 
mexicanos que orientaban al vicepresidente de la URSS acerca de la manera más idónea de gozar del tequila y, obviamente, de los tacos.

La imagen cómica y algo inapropiada de Mikoyán propuesta por LIFE en su reportaje no podría haber sido más engañosa. Detrás de las sonrisas y los movimientos desgarbados, se encontraba la visita oficial en suelo americano del político soviético más importante que jamás hubiera pisado América Latina. La presencia de Mikoyán en México representaba, en este sentido, una pieza fundamental de la estrategia de expansión de la influencia soviética en la región lanzada por Moscú a comienzo de $1956 .{ }^{1}$ Por otro lado, la cuidadosa atención mostrada por los funcionarios mexicanos hacia Mikoyán escenificaba la importancia que el huésped soviético tenía para el presidente Adolfo López Mateos y para el proyecto de desarrollo económico de un país cuya economía, hacia el final de la década de los años cincuenta, se encontraba algo estancada. En una nota que analizaba el resultado del viaje de Mikoyán, la revista Time afirmaba que “crisscrossing Mexico in President López Mateos' twinmotor Fairchild Fokker last week, the Soviet Union's first deputy Premier Anastás Mikoyán sold an image of Russia that was impressive and friendly". ${ }^{2}$

A pesar de los tacos y del tequila, la visita de Mikoyán había sido un asunto muy serio y, en cierta medida, un éxito para las relaciones diplomáticas bilaterales entre los dos países.

Como en la célebre película de Luis García Berlanga de 1953, Bienvenido Mr. Marshall, la visita de Mikoyán en 1959

1 SEwell, “A perfect (free-market) world?", p. 841.

2 "Mexico. Russian Headway", Time (7 dic. 1959), p. 36. 
anunciaba un horizonte de grandes posibilidades, dibujado por la posible expansión de las relaciones económicas y comerciales entre México y la URSS. Como en Bienvenido Mr. Marshall, donde tan esperada ayuda estadounidense se asoma y, sin embargo, pasa de largo de un expectante y polvoriento pueblo español de la época franquista, las promesas encubiertas en la visita del estatista soviético en México tampoco llegaron a cumplirse.

Basado en documentación inédita procedente tanto de archivos de la ex Unión Soviética, como de Estados Unidos y México, este artículo tiene por objeto analizar la parábola que durante los años de la presidencia de López Mateos condujo del clima de entusiasmo de noviembre 1959 al fracaso del proceso de acercamiento entre México y la URSS, evidente a partir de $1962 .{ }^{3}$ En particular, este artículo mostrará cómo, entre el final de la década de 1950 y el principio de los años sesenta, una serie de factores crearon por primera vez desde el comienzo del conflicto bipolar en 1947 las condiciones para un posible acercamiento entre los dos países. $\mathrm{Al}$ mismo tiempo, el trabajo mostrará que la fuerte dependencia comercial mexicana de Estados Unidos, posibles conflictos internos en el establishment político mexicano acerca del proceso de aproximación, aunados a las dificultades político logísticas soviéticas en proyectar su influencia económica en

\footnotetext{
${ }^{3}$ Este artículo retoma, desarrollándolo y ampliándolo significativamente, tanto en términos documentales como de interpretación, un texto de introducción a documentación soviética inédita sobre México publicado en agosto de 2015 por el Cold War International History Project del Wilson Center. PetTinà, "Mexican-Soviet relations", en Cold War International History Project, https://www.wilsoncenter.org/publication/ mexican-soviet-relations-1958-1964-the-limits-engagement\#_ftn3
} 
la región obstaculizaron el proceso de acercamiento entre los dos países.

Para mostrar los problemas políticos y logísticos del acercamiento, este trabajo analizará el episodio de la problemática venta de unos tractores soviéticos a México, que se dio como parte del proceso de posible convergencia económica entre los dos países. Como veremos, las dificultades que implicó tanto desde un punto de vista económico como político la venta y entrega de los tractores muestran de forma evidente las limitaciones con las que se enfrentó la Ostpolitik mexicana hacia la URSS y viceversa.

Cabe sin embargo mencionar que, a pesar de este fracaso, los ensayos de acercamiento entre los dos países resultaron fundamentales para crear las bases de la convergencia que se dio durante la década de los setenta, cuando durante la presidencia de Luis Echeverría Álvarez (1970-1976) México y la URSS firmaron una serie de tratados y convenios de cooperación económica. ${ }^{4}$ Como habría de ocurrir con el acercamiento al Tercer Mundo, el trabajo realizado durante el sexenio de López Mateos, a pesar de no tener un impacto inmediato, abrió el camino para una mayor convergencia durante la década posterior. ${ }^{5}$

La historia de las relaciones entre México y la Unión Soviética después de la segunda guerra mundial y, en particular, a lo largo de la década de 1960, ha recibido escasa atención, tanto por parte de la historiografía mexicana como de la internacional. Además, por las fechas en que se elaboraron,

${ }^{4}$ H. CÁRdenas, Historia de las relaciones, p. 227.

5 Sobre las políticas de acercamiento de México al Tercer Mundo durante la década de 1960 véase PetTinà, "Global Horizons”. 
las pocas obras producidas al respecto no tuvieron la oportunidad de utilizar fuentes primarias soviéticas o de combinarlas con material de archivo de otros países. ${ }^{6}$ En gran medida, esta laguna historiográfica es consecuencia de un problema más general de escasez de trabajos sobre la historia internacional de México durante el periodo conocido como Guerra Fría y, sobre todo, a lo largo de la década de $1960 .^{7}$ Se trata, con la notable excepción de los estudios sobre las relaciones entre México y la revolución cubana, de un vacío preocupante considerando que, a partir de 1958, la política exterior mexicana experimentó un importante ensanchamiento de su radio geográfico. ${ }^{8}$ De hecho, este proceso no sólo condujo a un acercamiento entre México y la URSS, sino que vio al

\footnotetext{
${ }^{6}$ A la fecha, la historiografía sobre el tema se ve sustancialmente reducida a unas pocas contribuciones, publicadas entre los años setenta y la década de los años noventa y que se caracterizan por el escaso uso de fuentes primarias. Ésta se compone de un volumen publicado en forma conjunta por la Secretaría de Relaciones Exteriores de México y la Academia de la Ciencia de la ex Unión Soviética, que recopila documentos oficiales bilaterales producidos entre 1917 y 1980; un libro de Héctor Cárdenas sobre la historia de las relaciones bilaterales que, sin embargo, dedica poca atención a los años sesenta. Finalmente, cabe señalar, un artículo publicado al comienzo de la década de 1970 por Blanca Torres que analiza la evolución de las relaciones comerciales entre México y el bloque socialista entre 1945 y el final de los años sesenta. L. Cárdenas y Sizonenko, Relaciones Mexicano-Soviéticas; Cárdenas, Historia de las relaciones; TorRes, "México en la estructura del comercio".

7 Excepciones a la falta de estudios de historia internacional sobre el periodo son, por ejemplo, Torres, De la guerra al mundo; OJEDA, Alcances y límites; Meyer, "La Guerra Fría en el mundo periférico".

8 Sobre las relaciones entre Cuba y México véanse Keller, Mexico's Cold War y "A foreign policy for domestic consumption"; CovarruBIAS, "Las relaciones México-Cuba"; OJeda, Alcances y límites; PelliCER, México y la Revolución cubana.
} 
país aproximarse también a nuevas áreas geográficas, como Asia y Oriente Medio, y a nuevos actores, como el Movimiento de los Países No Alineados. ${ }^{9}$ Como se ha mencionado antes, muchos de los pasos dados durante este periodo fueron retomados en la década de 1970, cuando México no sólo estableció relaciones comerciales y políticas más sólidas con la URSS, sino que jugó un papel central como líder de los países en desarrollo.

En este trabajo se mostrará que la globalización de la política exterior del país y, en ese ámbito, el acercamiento con la URSS, respondió a un intento de diversificar las relaciones políticas y comerciales mexicanas. El incremento de los contactos con Moscú aconteció en una coyuntura que, como la del final de la década de los años cincuenta, se había tornado en particular compleja para los proyectos de desarrollo económico de los países periféricos. Para México, la falta de recursos para proseguir con la industrialización, el desajuste de la balanza de pagos y la volatilidad de los mercados para productos primarios amenazaban con interrumpir el proceso de industrialización por sustitución de importaciones comenzado de forma sistemática a partir de 1946. La política exterior mexicana intentó responder a esta coyuntura al llevar a cabo una estrategia de diversificación de las relaciones políticas y comerciales del país que, entre otros pasos, incluyó el inédito, aun cuando incompleto, intento de acercamiento a la URSS. A pesar de las dificultades que el proceso encontró en su fase de realización, su estudio permite

\footnotetext{
${ }^{9}$ Sobre el tema del acercamiento al Movimiento de los Países No Alineados, véase, por ejemplo, Torres, De la guerra al mundo; Pettinà, "Global Horizons".
} 
apreciar a una clase política dotada de una visión estratégica compleja e imaginativa, que trascendía la dimensión de la mera relación bilateral con Estados Unidos, e incluso la interamericana, para abarcar una escala genuinamente global.

Por otro lado, a partir del caso mexicano, este trabajo apunta a reconstruir algunos aspectos cruciales del proceso de interacción entre la URSS, el bloque socialista y América Latina entre el final de los años cincuenta y la primera mitad de la década de 1960. A lo largo de los últimos años, y en especial a partir de los trabajos de Odd Arne Westad, ha habido un fuerte aumento de interés por parte de los historiadores para las relaciones entre la URSS y el Tercer Mundo. Sin embargo, América Latina ha quedado básicamente deslindada de este proceso, en gran medida por la presencia de una fuerte inercia que ha visto la mayor parte de los trabajos de historia internacional concentrarse en las relaciones entre el continente y Estados Unidos. Aunque gracias a las investigaciones recientes de autores como Michelle Getchell o Tobias Rupprecht ha habido un avance importante en la reconstrucción de las dinámicas de interacción entre América Latina y el campo socialista y, por ende, una actualización de una bibliografía bastante vetusta, éste sigue siendo un campo poco desarrollado de la historiografía. ${ }^{10}$ Este trabajo, enfocado al estudio del caso mexicano, busca mostrar y documentar la presencia de un fuerte interés soviético para fortalecer las relaciones comerciales y políticas entre la URSS y el continente latinoamericano. Por otro lado, el trabajo intenta contextualizar el proceso de fortalecimiento de los

10 Getchell, "Revisiting the 1954 Coup in Guatemala"; Rupprecht, "Socialist high modernity" y Soviet internationalism after Stalin. 
lazos con México como parte de la más amplia estrategia soviética de acercamiento al Tercer Mundo llevada a cabo por el liderazgo postestaliniano de Khrushchev. Finalmente, el presente estudio apunta a mostrar los límites políticos y logísticos con los cuales se enfrentó la política de acercamiento soviético al hemisferio occidental.

Por medio del estudio de este proceso, el presente trabajo tiene como objetivo contribuir a una "normalización" de la historia internacional de América Latina, integrando al análisis más ortodoxo de las relaciones del continente con Estados Unidos un ángulo distinto y poco visitado, como es el de la interacción con la URSS y el bloque socialista. La esperanza es contribuir a delinear una imagen más rica y completa de la trayectoria del continente latinoamericano y de México a lo largo del periodo que conocemos como Guerra Fría.

\section{LA URSS Y EL ACERCAMIENTO AL TERCER MUNDO}

El 18 de noviembre de 1959, un Ilyushin 18 turbohélice, última joya tecnológica de la aeronáutica comercial soviética, aterrizaba en la Ciudad de México. A bordo se encontraban Anastás I. Mikoyán y un nutrido grupo de 29 acompañantes que incluía a la esposa del líder soviético. Una multitud de aproximadamente 400-500 personas, encabezada por el secretario de Relaciones Exteriores de México, Manuel Tello, recibía a Mikoyán agitando claveles rojos y con gritos de "viva la Unión Soviética". ${ }^{11}$ La presencia en México del dirigente soviético más importante que jamás hubiera visitado América Latina representaba un aparente éxito de la nueva

11 “Mikoyán Arrives in Mexico City”, Chicago Tribune (19 nov. 1959), p. 3. 
estrategia de acercamiento al Tercer Mundo lanzada por la élite posestalinista y un nuevo horizonte de posibilidades para el país latinoamericano.

Como ha afirmado Vladislav M. Zubok, la política exterior soviética durante la Guerra Fría estuvo conformada tanto por elementos que recuperaban la herencia imperial zarista, como por nuevas formas de conceptualizar el papel internacional de Moscú, emergidas de la experiencia revolucionaria y de la ideología comunista soviética. Con Stalin, lo que Zubok ha definido como el "paradigma revolucionarioimperial" se había inclinado decididamente hacia la vertiente realista, pragmática e imperial de este binomio. Convencido de la inevitabilidad de un próximo conflicto con Occidente, la estrategia estalinista se había concentrado en la construcción de una configuración geopolítica de Europa que pudiera garantizar a medio plazo la seguridad soviética. La sovietización de Europa Oriental que ocurrió entre 1946 y 1948 respondió a esta visión estratégica que apuntaba a "sellar" los confines occidentales del imperio soviético. Se trataba de una perspectiva que giraba alrededor de la cuestión estratégica euroasiática, con tintes de paranoia aislacionista en que el internacionalismo y, por ende, la atención hacia el Tercer Mundo no encontraba grandes espacios. ${ }^{12}$

Con la muerte de Stalin en 1953 y la llegada al poder de una nueva dirigencia encabezada por Khrushchev, la estrategia internacional de Moscú rompió con un giro radical el realismo y el aislamiento de la era tardo estalinista, volviendo a

12 Sobre el problema de la evolución de política exterior durante Stalin y después de su muerte, véase RuPPRECHT, Soviet internationalism after Stalin; Zuвок, A Failed Empire; Graziosi, L'URSS dal Trionfo al Declino. 
recuperar con fuerza su carácter utópico e internacionalista, inspirado en la revolución y su capacidad transformadora. Así pues, a partir de 1953 la URSS empezó a intentar desplazar el conflicto con Washington desde el plano del enfrentamiento militar a uno de competición de modelos sociales y económicos. La doctrina de la coexistencia pacífica, lanzada por Khrushchev en 1956, en el marco del XX Congreso del Partido Comunista de la URSS, se proponía bajar las tensiones bipolares y ganar la partida con Occidente a partir de la convicción de la superioridad del modelo socioeconómico soviético sobre el capitalista occidental. Estrictamente vinculada a este replanteamiento estuvo la decisión de Khrushchev de apostar con fuerza sobre el Tercer Mundo como posible terreno propicio para mudar las relaciones de fuerzas con Occidente a favor de Moscú. En el Tercer Mundo, despojado por el imperialismo occidental y necesitado de insumos materiales e ideológicos para construir su desarrollo económico, la URSS podía mostrar la superioridad de su modelo sobre el de Washington y con el tiempo mover los nuevos países hacia la adopción de modelos socialistas.

Con Khrushchev, la política exterior de la URSS recuperaba la atención que Moscú había comenzado a conferir al Tercer Mundo, y a Asia en especial, durante los años veinte. Aunque en esta fase el mundo colonial mantuvo un papel secundario en la estrategia soviética, es cierto que el escrito de Lenin El imperialismo, fase suprema del capitalismo mostraba que anticapitalismo y antiimperialismo estaban íntimamente ligados en la elaboración ideológica soviética. ${ }^{13}$

${ }_{13}$ Friedman, Shadow Cold War, p. 13; Westad, The Global Cold War, pp. 50-52. 
En 1920, el Segundo Congreso del Comintern había adoptado la tesis leninista del "camino no capitalista de desarrollo", que planteaba la posibilidad de que las colonias pudieran alcanzar el socialismo sin necesidad de pasar por la fase capitalista de desarrollo. Además, como puso de relieve el conflicto entre el propio Lenin y el delegado hindú Manabendra Nath Roy, el Comintern había planteado la posibilidad de alianzas entre las fuerzas comunistas y la burguesía progresista anticolonial para acelerar el proceso de revolución antiimperialista en las colonias. ${ }^{14}$ Sin embargo, en la década de 1920 la URSS no estaba en condiciones materiales de apoyar los procesos descolonizadores y, además, como hemos destacado, la consolidación de Stalin en el poder sancionó un periodo de larga desatención por parte soviética hacia las realidades periféricas.

A partir del XX Congreso los ideólogos soviéticos concentraron su actividad en la elaboración de un nuevo andamiaje ideológico para facilitar la interacción con el Tercer Mundo. En la Declaración de Moscú de 1960 se introdujo el concepto de "estados nacional-democráticos" y se recuperó la teoría del "camino no capitalista de desarrollo" como fundamentos de la política exterior soviética hacia las periferias. ${ }^{15}$ A partir de estos conceptos, la URSS establecía la posibilidad para los partidos comunistas locales de establecer alianzas con las fuerzas y los gobiernos de la burguesía nacional emergidos de la descolonización, o con los de América Latina empeñados en llevar a cabo una estrategia de modernización económica de los respectivos países.

14 Westad, The Global Cold War, p. 52.
${ }^{15}$ Friedman, Shadow Cold War, p. 71. 
El papel de los comunistas en estos contextos tenía que ser el de empujar progresivamente a la burguesía hacia un programa de desarrollo económico no capitalista. Para Moscú, políticas concretas como la aplicación de leyes de reforma agraria y la industrialización liderada por el Estado eran cruciales para alcanzar una verdadera independencia política y, posteriormente, para la implantación del socialismo. En particular, para los teóricos soviéticos la expansión de la industria pesada estatal habría modificado desde abajo las estructuras sociales de los países del Tercer Mundo generando las fuerzas y los actores necesarios para una transformación socialista. Como recuerda Engerman, la economía de Estado representaba una estrategia progresista en el marco teórico soviético de la mitad de los años cincuenta, en la medida en que favorecía la industrialización y deslegitimaba los teoremas clásicos del capitalismo occidental. ${ }^{16}$ El papel de la URSS tenía que ser el de proporcionar ayuda técnica, comercial y económica para que los países del Tercer Mundo adoptaran planes de industrialización estatal, formas de planificación económica y políticas de nacionalización. ${ }^{17}$

Dentro de este marco, por un lado la URSS apoyó al movimiento de descolonización en Asia, Oriente Medio y África, sosteniendo la creación de frentes de liberación nacionales liderados por fuerzas nacionalistas y que no necesariamente tenían que incluir o ser encabezados por comunistas. Por otro lado, Khrushchev lanzó una agresiva política de ayuda económica, técnica y de expansión de las relaciones comerciales con los gobiernos nacionalistas de los países del Tercer

16 Engerman, "Learning from the East", p. 232.

17 Friedman, Shadow Cold War, pp. 39 y 73-74. 
Mundo, como India, Indonesia, Burma, Afganistán, Egipto, Congo o Mali. Por lo menos en esta primera fase la estrategia de Khrushchev se veía aventajada por el hecho de que el modelo socioeconómico soviético, basado en un proceso de modernización económica liderado por el Estado, se adaptaba mejor que la receta liberal capitalista a las exigencias de los países del Tercer Mundo. De alguna forma, la URSS respondía a la necesidad del Tercer Mundo global, incluyendo a América Latina, de acelerar su proceso de desarrollo en condiciones de desventaja o "retraso" por medio de su propia experiencia histórica. La transformación planificada de país agrícola a potencia industrial, acontecida en un lapso de tiempo extremadamente corto y en condiciones de dificultad dramáticas, representaba un poderoso passe-partout para los corazones y las mentes de los líderes del Tercer Mundo.

Como han destacado autores como Artemy Kalinovsky, los avatares de la nueva estrategia soviética dieron sus primeros pasos en países de Asia Central, como Tayikistán y Uzbekistán, que se encontraban dentro de la órbita de influencia de la URSS y donde Moscú puso a prueba sus recetas para el desarrollo económico de regiones menos avanzadas. ${ }^{18}$ Aunque hasta el triunfo de la revolución cubana la acción soviética se mantuvo concentrada por razones de cercanía geográfica y de geopolítica en Asia, Oriente Medio y África, América Latina no quedó exenta de las atenciones de Moscú y, a partir de 1953, el continente fue progresivamente englobado a la par de otras áreas periféricas en la estrategia de acercamiento del Kremlin hacia el Tercer Mundo.

18 Kalinovsky, "Not Some British Colony”. 
El primer país en estrechar lazos más cercanos con la URSS fue Argentina que, en agosto de 1953, firmó un tratado comercial y de pago para aumentar los niveles de interacción comercial con el bloque socialista. A comienzos de 1956, el premier soviético Nikolai Bulganin formalizó oficialmente la oferta soviética de ayuda económica y de ampliación de vínculos comerciales con América Latina. A raíz de este giro, para el final de la década, la interacción entre América Latina y el bloque socialista había aumentado de forma importante. ${ }^{19}$ En 1958, Argentina tenía firmado con Polonia un acuerdo para adquirir maquinaria y carbón a cambio de quebracho, cueros, lanas y aceite de linaza. Además, el país tenía suscritos varios acuerdos bilaterales con Alemania Oriental, Bulgaria y Rumania, con un intercambio total estimado de varias decenas de millones de dólares. Finalmente, en el marco de estos acuerdos, para cubrir el saldo comercial deficitario, la URSS ofreció vender a Argentina equipo petrolero estimado en 100000 de dólares y 1000000 de toneladas de petróleo. Moscú también decidió establecer una línea de crédito de 100000000 de dólares para financiar futuras importaciones. Durante el mismo periodo, Brasil vio aumentar significativamente sus intercambios comerciales con Moscú y los otros países del bloque socialista. ${ }^{20}$

Evidentemente, el triunfo de la revolución cubana en 1959 y la adopción por parte de Cuba de un régimen político de tipo socialista e ideológicamente alineado con la URSS ofrecieron nuevos estímulos para la ampliación de

\footnotetext{
19 Torres, "México en la estructura del comercio".

20 "El comercio de América Latina con los países comunistas", Comercio Exterior (nov. 1959), pp. 630-632.
} 
las relaciones con el continente y aumentaron el optimismo de la leadership política soviética sobre los posibles resultados de su estrategia de acercamiento a América Latina. Como argumentaba el vicepresidente del comité de Estado para las relaciones económicas de la URSS, Dmitrij Danilovich Degtyar, al margen de una visita de buena voluntad realizada en América Latina en el verano de 1961, la revolución cubana significó la ruptura de "la teoría del fatalismo geográfico introducida por la propaganda norteamericana", que implicaba la inevitable pertenencia de América Latina a la órbita estadounidense. ${ }^{21}$

Para aprovechar las nuevas oportunidades generadas por la revolución cubana, en 1961, la URSS creaba el Instituto de América Latina de la Academia de Ciencias, un centro de análisis y de estudio sobre el continente cuyas investigaciones habrían de guiar la elaboración y puesta en marcha de la política soviética hacia el continente. El instituto se sumaba a la preexistente sección latinoamericana del Instituto de Historia de la Academia y su creación fue seguida por la fundación de numerosas instituciones académicas dedicadas al estudio del continente latinoamericano. ${ }^{22}$

El elemento que en una fase inicial dio fuerza a la iniciativa política de Moscú hacia América Latina fue la fuerte complementariedad entre el análisis de los investigadores de la

${ }^{21}$ RGAE, D.D. Degtyar (1904-1982), fondo Personal, Fond 645, Opis 1, Delo 31, "Reportes sobre el viaje a América Latina, Reporte sobre el viaje de Buena Voluntad de la Delegación Soviética a los Países Latinoamericanos", sin fecha, aprox. 1961-1962, pp. 143-144.

${ }^{22}$ Fazio Vengoa, “América Latina vista por los académicos", p. 33; Rupprecht, Soviet internationalism after Stalin, pp. 28-34; Miller, Soviet relations, p. 11. 
Academia de Ciencias acerca de los problemas socioeconómicos continentales y las teorías sobre desarrollo económico elaboradas por los propios economistas latinoamericanos, en particular por la Comisión Económica para América Latina (CEPAL), presidida entre 1949 y 1963 por Raúl Prebisch. "La independencia económica es el objetivo principal de los países latinoamericanos [...] y la base de la independencia económica es el desarrollo de la economía nacional y, primero de todos, la industria", afirmaba un reporte elaborado por los especialistas soviéticos de la Academia de la Ciencia a principios de los años sesenta en consonancia con lo establecido por la Declaración de Moscú. Para alcanzarla, el documento enumeraba una serie de medidas que recordaban las recetas desarrollistas latinoamericanas e indicaba que el continente necesitaba superar una excesiva especialización que relegaba a América Latina a "apéndice subordinada de materias primas para los países capitalistas industrialmente avanzados". En el reporte, los analistas soviéticos insistían particularmente en el peso de los monopolios estadounidenses en sus intentos por "mantener la diferenciación internacional del trabajo" y que frenaban el desarrollo económico del continente. Según el documento, las teorías económicas neoclásicas "de la interdependencia y de las economías complementarias", a su vez basadas "sobre la viciosa idea de los costos relativos", mantenían a los países latinoamericanos en una posición de subordinación política y económica respecto a Estados Unidos. Para superar esta condición, continuaba el análisis de los latinoamericanistas soviéticos, los países del continente tenían que avanzar en su proceso de desarrollo industrial aumentando el poder de control del Estado sobre las inversiones privadas hasta su eliminación y reforzando 
su capacidad de promoción material de la industrialización. Además, para el documento era esencial implementar la reforma agraria y luchar por el establecimiento de unas relaciones comerciales más equilibradas con el resto de los países del mundo y con los países socialistas en primera instancia. ${ }^{23}$

El documento soviético, apéndice latinoamericano de la estrategia de desarrollo no capitalista, seguía de cerca las reflexiones que Prebisch había ido realizando desde sus visitas y seminarios en México a partir del final de los años cuarenta (en 1944 en El Colegio de México y en 1946 en el Banco de México) y, con más sistematicidad, desde su posición de director de la CEPAL. Cepalinos y especialistas soviéticos compartían la idea de que los términos de comercio internacional desfavorables para los productos primarios de las periferias y el carácter en cierta medida monopólico de la economía internacional determinaban una condición de vulnerabilidad estructural de los países latinoamericanos. Como afirmó Víctor Urquidi, director de la sede de la CEPAL en México entre 1951 y 1958, para acelerar el desarrollo económico de los países del continente la CEPAL sugería una estrategia de industrialización programada por el Estado que implicaba la introducción de medidas proteccionistas, reformas agrarias, inversiones estatales, atracción de capitales extranjeros y préstamos públicos y privados. Este conjunto de políticas coordinadas por el Estado tenía por objeto coadyuvar en la creación de industrias siderúrgicas, automovilísticas, eléctrica, petroquímica, y para mejorar las

${ }^{23}$ RAS, Fond 1798, Opis 1, Delo. 88, "Algunos Problemas de Independencia Económica de América Latina”, sin fecha, aprox. 1960-1961, pp. 45-65. 
infraestructuras nacionales. ${ }^{24} \mathrm{La}$ CEPAL, con más énfasis que los expertos soviéticos, planteaba la necesidad de alentar las inversiones privadas para acelerar el desarrollo económico. Sin embargo, los economistas de la agencia de la ONU reconocían, a la par de los soviéticos, la necesidad por parte del Estado de intervenir profundamente en la planificación económica, en especial en los sectores inicialmente no rentables para la iniciativa privada. Para ambos, el subdesarrollo era superable sólo por medio de una industrialización que los soviéticos definían como "planificada” y los cepalinos como "programada". 25

A partir de sus análisis y del énfasis puesto en el papel del Estado en la planificación económica y en la industrialización, los teóricos de la Academia de la Ciencia habían identificado un fuerte punto de ventaja que la URSS tenía sobre Estados Unidos para acercarse con éxito al Tercer Mundo y, en este caso, a los países latinoamericanos. Como recordaba en un informe Zinaida Ivanovna Romanova, una de las principales expertas de asuntos latinoamericanos de la Academia de la Ciencia, los países latinoamericanos, para poderse industrializar en un contexto desigual y en presencia de los monopolios estadounidenses, necesitaban reforzar el papel del Estado como promotor del proceso industrializador. Washington, según el documento, por razones ideológicas y de interés económico tradicionalmente se había mostrado reluctante en apoyar ese sector de la economía y, en cambio, había privilegiado estrategias de fortalecimiento de los

24 Urquid, Otro siglo perdido, p. 123.

25 Dosman, The Life and Times, p. 276; Love, “The Rise and Fall”, pp. 161-167. 
flujos de inversión privada. El análisis de la Romanova era acertado, considerando que desde la Conferencia Interamericana de Chapultepec, en 1945, el debate sobre modelos de desarrollo divergentes había representado una herida abierta en las relaciones entre norte y sur del continente americano. ${ }^{26}$

En este sentido, como destacaba Romanova, respecto a Estados Unidos los países socialistas tenían la ventaja de poder asistir el sector estatal de las economías latinoamericanas sin reticencias, justamente en virtud de una ideología que compartía la necesidad de estatalización de la economía. ${ }^{27}$ De hecho, como lo subraya Sánchez-Sibony, la URSS mostró a partir de la mitad de los años cincuenta una disponibilidad mucho mayor que Estados Unidos para apoyar los proyectos de sustitución de importaciones liderados por el Estado, no solamente en América Latina, sino, más en general, en el Tercer Mundo. Por medio de herramientas como préstamos a $2.5 \%$, rembolsables en 12 años mediante la compra de productos o servicios procedentes del bloque socialista o por exportaciones locales, la URSS se dotaba de mecanismos aptos para la financiación de empresas que necesitaban tiempo para volverse rentables y que, por ende, eran inicialmente poco atractivas para la inversión privada y necesitaban apoyo estatal. ${ }^{28}$

26 Helleiner, "Reinterpreting Bretton Woods"; Bethell y RoxboROugh, "The Impact of the Cold War”, p. 313; PetTinà, “Adapting”, pp. 1-2; URQUIDI, Otro siglo perdido, pp. 122-126.

27 RAS, Fond 1798, Opis 1, Delo 88, Z. I. Romanova "Cooperación Económica de América Latina con el Bloque Socialista”, pp. 124-130. Sobre este tema, véase también SÁNCHEZ-SibOny, Red Globalization, p. 133.

28 Sánchez-Sibony, Red Globalization, p. 132; United States. Department of State, "Current Communist Strategy". 
Desde el punto de vista soviético, la década de los sesenta se abría con un gran optimismo generado tanto por la convergencia teórica entre la estrategia soviética y los planes de desarrollo latinoamericanos, como por hechos como la revolución cubana, que parecían demostrar la inevitabilidad del triunfo de la URSS. Sin embargo, como veremos, el optimismo de los primeros años sesenta se enfrentó muy pronto con los escollos de una realidad que planteaba problemas logísticos y políticos muy serios para la ampliación de la influencia soviética en América Latina y México.

MÉXICO Y LAS OPORTUNIDADES DE LA DIVERSIFICACIÓN

El Ilyushin de Mikoyán aterrizaba en un México que a partir de los años de la segunda guerra mundial había avanzado dramáticamente en el proceso de transformación socioeconómica del país. Como lo ha destacado Soledad Loaeza, el "milagro mexicano" alteró de forma dramática "la fisonomía" del país: "se construyeron gasoductos, zonas industriales, sistemas hidroeléctricos, obras portuarias, áreas residenciales, colonias obreras". ${ }^{29}$ Por medio de una exitosa política de industrialización por sustitución de importaciones, puesta en marcha de forma sistemática a partir de la administración de Miguel Alemán (1946-1952), entre 1950 y 1962 el país vio su PIB crecer en $6 \%$ anual; la producción de bienes se duplicó respecto a 1940 y la industria llegó a representar $35 \%$ del producto nacional. ${ }^{30}$ Durante estos años, el Estado

29 LoAezA, “Modernización autoritaria”, p. 675.

30 NARA, RG59, 712.00/6-1362, "Mexico and the Alliance for Progress", 3 de junio de 1962 . 
federal mexicano amplió sus funciones regulatorias y su participación activa en la promoción industrial, sin descuidar el papel de la inversión privada. A pesar de la fuerte desigualdad generada por las características del modelo de desarrollo mexicano, gracias al crecimiento económico y a la ampliación del aparato burocrático del Estado, el país registró una fuerte movilidad social, evidenciado en el aumento de su clase media, que entre 1940 y el final de la década de los sesenta pasó de representar $16 \%$ de la población a 26 por ciento. ${ }^{31}$

Sin embargo, al final de la década de 1950, el modelo de desarrollo mexicano había empezado a registrar profundos problemas. En particular, la disminución de los volúmenes y de los precios de las exportaciones, sobre todo algodón y café, habían empezado a crear graves y crecientes desequilibrios en la balanza de pagos, debilitando el ingreso de divisas necesarias para la adquisición de aquellos capitales que el país requería para alimentar el proceso de industrialización. Según datos estadounidenses, para 1961, el crecimiento anual del PIB había bajado a $3.5 \%$, un dato alarmante para un país con una expansión demográfica anual de 3 por ciento. ${ }^{32}$

Como se ha argumentado en otro lugar, la administración de López Mateos imputaba las dificultades del país a los desequilibrios del sistema económico internacional que, en virtud del proteccionismo del centro y a causa de los términos desfavorables para los productos primarios, obstaculizaba

31 Walker, Waking from the Dream, p. 3. Véase también LoAeza, Clases medias.

32 NARA, RG59, 712.00/6-1362, "Mexico and the Alliance for Progress", 3 de junio de 1962. Vernon, The Dilemma of Mexico's Development, p. 117; LOAEZA, "Modernización autoritaria", pp. 665 y 669; E. CÁrdenas, "La economía”, p. 517. 
los procesos de desarrollo de los países periféricos. ${ }^{33} \mathrm{De}$ hecho, el problema de las balanzas de pagos desequilibradas a causa de la inestabilidad de los mercados para productos primarios o la falta de capitales y divisas amenazaba, al final de los años cincuenta, no sólo a los países latinoamericanos como México. La India de Nehru, empeñada como México en un complejo proceso de industrialización por sustitución de importaciones, se encontraba al comienzo de su segundo plan quinquenal en condiciones parecidas $y$, como México, en búsqueda de alternativas. ${ }^{34}$ En el caso mexicano, parte de las distorsiones criticadas por el presidente López Mateos eran imputables a la asimetría económico comercial que México mantenía con Estados Unidos, su principal socio comercial, y planteaban la necesidad de transformación de esta condición de dependencia. ${ }^{35}$

A raíz de este análisis del contexto económico internacional, el comienzo de la presidencia de López Mateos fue marcado por una estrategia que apuntaba a la ulterior nacionalización y estatalización de la economía, además de a la búsqueda de una mayor diversificación comercial. En enero de 1959, el presidente había emitido un decreto que obligaba a todas las oficinas y agencias del gobierno y a las empresas con participación estatal a utilizar sólo insumos de origen mexicano en lugar de importados. Las empresas privadas mexicanas ya habían sido objeto de una política

33 Pettinà, "Global Horizons”, pp. 6-7.

${ }^{34}$ Sobre la crisis cambiaria hindú al comienzo de su segundo plan quinquenal véase SÁnchez-Sibony, Red Globalization, p. 160.

${ }^{35}$ En 1965, 64.2\% de las importaciones mexicanas procedían de Estados Unidos y 71.2 de su producción era exportada al mercado estadounidense. González Casanova, La democracia en México, p. 179, nota 7. 
de restricciones en sus importaciones que, ahora, el decreto extendía al sector público. Como destacaba una nota de la embajada estadounidense en México, el decreto en sí mismo no era importante, sino el hecho de que la medida mostraba “el celo con que la nueva administración mexicana quiere implementar su anunciada política de reducción de las importaciones al mínimo conmensurado con las necesidades de industrialización y desarrollo del país". ${ }^{36}$ La ley de nacionalización del sector eléctrico del país, emitida en septiembre de 1960, y una nueva legislación que obligaba a las empresas mexicanas productoras de materias primas o estratégicas a tener $51 \%$ de capital mexicano, completaron el cuadro interno de medidas orientadas a la nacionalización de la economía. ${ }^{37}$

En el plano externo, la nueva estrategia de diversificación había llevado a México a intensificar su interacción con los países de la región. En enero y febrero de 1959, López Mateos realizó un "gran tour” por América Latina: Venezuela, Brasil, Argentina, Chile, Bolivia y Perú con el objeto, según la embajada estadounidense en México, "de promover las relaciones comerciales entre México y América Latina”. La entrada de México en la Asociación Latinoamericana de Libre Comercio, creada por el Tratado de Montevideo en febrero de 1960, completó el marco regional de la estrategia de diversificación económica. ${ }^{38}$

36 NARA RG59, 712-00/2-1359, "Monthly Economic Summary, January -1959”, 13 de febrero de 1959, p. 11.

37 Torres, México y el mundo, p. 138; LoAezA, "Modernización autoritaria”, pp. 683-684. NARA RG59, 712-00/2-1359, “Monthly Economic Summary, January -1959”, 13 de febrero de 1959, p. 11.

38 NARA RG59, 712.00(W)/12-3159, “Joint Weeka no. 51-52. December 16-31 1959”, 31 de diciembre de 1959. 
El activismo de la presidencia de López Mateos no se limitó al ámbito interamericano y condujo a México a estrechar nuevas relaciones con países como Indonesia, India, Filipinas y Japón. Además, el presidente de México llevó a cabo un acercamiento prudente con el Movimiento de los Países No Alineados, un actor que buscaba modificar las estructuras económicas internacionales en términos más favorables para los procesos de desarrollo periféricos. En el último minuto México decidió no participar en la Conferencia de Países No Alineados celebrada en Belgrado durante agosto y septiembre de 1961 y, en cambio, sí tomó parte en la conferencia sobre asuntos económicos celebrada en El Cairo en 1962. ${ }^{39}$

La visita de Mikoyán se daba justamente en el contexto de estas dificultades y en el marco del proceso de diversificación lanzado por la presidencia de López Mateos. De la documentación diplomática mexicana se puede apreciar el interés con el cual ya desde 1958 las autoridades del país seguían, por medio de la embajada mexicana en la URSS, el acercamiento soviético a América Latina. Los diplomáticos mexicanos, por ejemplo, monitorearon de cerca, informando oportunamente a la Secretaría de Relaciones Exteriores, el proceso que entre 1958 y 1959 condujo a la firma de varios acuerdos comerciales y crediticios entre Moscú y Buenos Aires. En enero de 1958, la Secretaría de Relaciones Exteriores solicitaba a su sede diplomática en Moscú explicar en detalle en qué consistía exactamente la oferta soviética a Argentina "de abundantes créditos a largo plazo y muy bajo rédito" mencionada por el encargado de negocios mexicano en un telegrama. De igual forma, los diplomáticos mexicanos

39 Pettinè, “Global Horizons”. 
relataron con atención la disponibilidad soviética a ofrecer créditos y maquinaria para el desarrollo de la industria petrolera argentina, formalizada en un acuerdo comercial de mayo de $1959 .{ }^{40}$

En un largo artículo editorial publicado en Comercio Exterior se aclaraban de forma lúcida los elementos por los cuales México seguía con interés la evolución de las relaciones soviético argentinas. Según el editorialista, “el interés y los motivos que tuvieron varias repúblicas latinoamericanas para acrecentar su comercio con aquel grupo de países" se explicaba porque al concluir la Guerra de Corea "se empezaron a debilitar los mercados tradicionales de algunos productos primarios, y luego, con el paso del tiempo, se agravaron las dificultades del comercio latinoamericano de exportación”. El análisis de sabor cepalino del Banco Nacional de Comercio Exterior seguía indicando que "la experiencia reciente" había mostrado que la caída de la demanda para productos primarios no era coyuntural ni estaba simplemente "vinculada con la reducción cíclica de la actividad económica en los grandes centros industriales de Occidente, sino también con tendencias de más largo plazo”. La relación con el bloque socialista planteaba la posibilidad de "colocar una parte de los saldos exportables en nuevos mercados” y de recibir además "en contrapartida de las propias ventas [...]

40 SRE, III/510 (47-0) 959/2-5; III 1933-6, Informes Políticos Suplementarios, Dirección General del Servicio Diplomático, "Relaciones Comerciales entre la URSS y la Argentina", 17 de enero de 1958; Embajada Mexicana en Moscú, "Sin Título", núm. 70, 11 de enero de 1958; Informes Políticos, "Equipo y maquinaria soviética para el desarrollo de la industria petrolera argentina", Embajada Mexicana en Moscú, 6 de junio de 1959. 
los combustibles y bienes de capital que tanta falta hacían para el desarrollo económico". ${ }^{41}$

Desde el punto de vista mexicano, tanto la inauguración de la exposición técnica como las entrevistas con las autoridades soviéticas, representadas por Mikoyán, ofrecían una clara ocasión para sondear la disponibilidad y, sobre todo, la capacidad soviética para secundar la estrategia de diversificación mexicana. Desde el punto de vista de Moscú, la posibilidad de ampliar relaciones con un país tradicionalmente cercano a Estados Unidos y colocado en una posición geográfica de gran interés estratégico representaba un avance relevante en la estrategia de expansión de la influencia soviética en América Latina en detrimento de Washington. Además, México, que a raíz de la revolución de 1910 adoptó una forma de desarrollo económico marcadamente étatiste, bien se adaptaba en principio a los planteamientos de los teóricos soviéticos acerca de los procesos de cambio en el Tercer Mundo.

\section{LA EXPOSICIÓN SOVIÉTICA DE 1959}

Y EL ACERCAMIENTO A MÉXICO

Analistas y dirigentes soviéticos poseían un diagnóstico preciso tanto de las condiciones políticas internas mexicanas como de su colocación internacional y de los problemas económicos que el país estaba enfrentando entre el final de la década de 1950 y el comienzo de la de 1960. Un largo informe sobre México, elaborado por los analistas de la

41 "El Comercio de America Latina con los Países Comunistas", Comercio Exterior (nov. 1959), pp. 630-632. 
Academia de Ciencias en 1960, reconocía las características peculiares del funcionamiento del sistema político del país. Después de registrar la presencia de instituciones democráticas y el pluralismo político, el documento afirmaba su mero formalismo, reconociendo que el poder real en el país era detenido por el presidente y por el Partido Revolucionario Institucional (PRI), en su calidad de partido único. Desde un punto de vista económico, Moscú consideraba que México era "una economía comparativamente desarrollada de América Latina” puesto que no dependía de la venta en el mercado internacional de un solo producto primario. Sus reservas de minerales y su producción de petróleo, cobre y plata, constituían una base diversificada y, además, el documento recordaba el fuerte impulso dado a la industrialización, en especial en el sector energético, metalúrgico y de transformación. El elevado desarrollo tanto de la agricultura de consumo como de exportación completaba el cuadro de una economía que los soviéticos juzgaban relativamente diversificada y dotada de una compleja base productiva. Al mismo tiempo, los latinoamericanistas soviéticos subrayaban los niveles de pobreza extremos que caracterizaban el modelo de desarrollo mexicano, los elevados grados de analfabetismo y la fuerte dependencia comercial y financiera que el país mantenía con Estados Unidos.

De acuerdo con este análisis, el Estado mexicano controlaba buena parte de la economía nacional y, a pesar de la oposición de los círculos económicos y financieros internos conectados a Estados Unidos y del propio establishment estadounidense, la administración de López Mateos estaba determinada a aumentar por medio de una mayor intervención estatal los niveles de producción industrial y agrícola. 
Este tipo de políticas estatalistas internas, aunadas al intento de López Mateos de mantener una política exterior más autónoma que en el pasado respecto a Estados Unidos, habían generado "serios desacuerdos" entre México y Washington. ${ }^{42}$ En otro informe, el embajador soviético en México, Vladimir Bazykin, volvía a destacar el énfasis que, respecto a sus predecesores, la administración de López Mateos ponía en la cuestión de la industrialización liderada por el Estado y de la búsqueda de una mayor independencia relativa en el contexto internacional de Estados Unidos:

En comparación con el anterior, el actual gobierno de México, de manera más consistente busca la industrialización del país, en primer lugar, el desarrollo de las industrias petrolera, metalúrgica, eléctrica y química. En ello ve la paulatina liberación de la dependencia económica de Estados Unidos. Al mismo tiempo, se orienta a ampliar su mercado externo mediante la extensión de sus vínculos comerciales con los países de Europa, Asia, África y América Latina. El presidente López Mateos es partidario del establecimiento de contactos personales con los dirigentes de otros estados y en cierta medida pretende el liderazgo en América Latina. En relación con los Estados Unidos adopta una posición más valiente en comparación con sus predecesores. $^{43}$

${ }^{42}$ RGAE, Fond 645. Opis. 1. Delo. 31, pp. 445-450, "México (Nota Informativa)", ca. 1960.

${ }^{43}$ Se resuleve el pleito pero solo en 1960. AVP RF, Fond 110, Sin Inventario, sin exp., Material informativo, "V. Bazykin. Sobre las relaciones mexicano-soviéticas. Camarada A.A. Gromyko Acerca de las relaciones mexicano-soviéticas", No. 516/OCA, 3 de agosto de 1960, pp. 22-27. 
De alguna forma, la exposición y la visita de Mikoyán a México habían intentado insinuarse en medio de los desacuerdos con Estados Unidos y ofrecer al país latinoamericano herramientas económicas y comerciales para apuntalar su proceso de desarrollo económico liderado por el Estado, reducir su dependencia de Washington y aumentar, de paso, la influencia soviética en la región.

Un largo informe de la CIA acerca de las estrategias soviéticas en las periferias del mundo dedicaba un detallado apartado a la visita de Mikoyán a México y revelaba cómo su presencia en el país latinoamericano abría una nueva fase en la estrategia soviética de acercamiento a América Latina. "La visita del Vice Premier Mikoyán a México en Noviembre en conexión con la apertura de la exhibición industrial soviética - afirmaba el documento - marca una nueva fase en los intentos soviéticos de aventajarse de las dificultades económicas latinoamericanas para expandir el comercio y otros tipos de relaciones con el bloque." Además, el informe subrayaba que si antes Mikoyán había enfocado su acción hacia la promoción del comercio con la URSS, a partir de su visita a México sus intervenciones habían adquirido un carácter más político, y "sus comentarios privados y públicos en México estaban dirigidos tanto a aspectos políticos como económicos del 'colonialismo' - influencia estadounidense en América Latina”. Para la CIA, la nueva fase de la política soviética hacia América Latina dirigía con vehemencia "sus ataques en contra de las políticas y de las actividades de los Estados Unidos y de las empresas estadounidenses en América Latina" y los acompañaba con "la reiteración del interés soviético en aumentar el comercio y la disponibilidad en ofrecer 
- 'sin lazos' - créditos para el desarrollo a México y a otros países latinoamericanos". ${ }^{4}$

De acuerdo con las fuentes soviéticas, la contundencia de Mikoyán, relevada por el informe de la cia, y el intento de insinuarse entre las contradicciones políticas y económicas que habían marcado la relación bilateral entre México y Estados Unidos a partir de la presidencia de López Mateos, había tenido éxito. En su reporte acerca de los resultados generados por la exposición soviética inaugurada en la Ciudad de México en noviembre de 1959, el director de la exhibición, A. Shelnov, hacía alarde de una gran satisfacción:

La exhibición ha tenido un gran éxito entre los círculos empresariales de México. Durante un periodo de 25 días ha sido visitada por lo menos [por] un millón de personas. Entre los visitantes estuvieron los políticos y las figuras nacionales más importantes del país, delegaciones de representantes sindicales, maestros, estudiantes, comunidades campesinas, del ejército y la armada, etc. etc. Ha recibido reacciones favorables en la prensa mexicana, la radio y la televisión, y de esta forma ha tenido influencia también sobre la masa de mexicanos que han tenido oportunidad de visitarla en persona. Los asistentes han dejado miles de comentarios entusiásticos en el libro de visitas.

El leitmotiv subyacente en la exposición había sido mostrar el avance, el progreso y el futuro sin límites al que estaba destinada la URSS gracias a la revolución socialista y a los cambios sociales y económicos que ésta había propiciado en el país. En este sentido, los curadores soviéticos habían

${ }^{44}$ CIA-CREST, "Current Intelligence Staff Study. Soviet Policy Toward the Underdeveloped Countries”, 28 de abril de 1961, p. 90. 
organizado la exhibición de forma completa, acompañando las secciones que mostraban los últimos avances de la ciencia y de la técnica con otras dedicadas a la historia de la URSS y de sus avances sociales, económicos y culturales posteriores a 1917. Como recordaba Shelnov, la URSS había organizado antes del 59 tres grandes exhibiciones en América Latina, en 1946 en México para la feria internacional del libro y dos de carácter industrial en Argentina, en 1955 y 1957 respectivamente. Sin embargo, esta era la "primera exhibición soviética en países latinoamericanos que ofrecía una amplia cobertura de distintos aspectos de la vida del Estado soviético". Así pues, la primera sección de la exhibición estaba dedicada a la descripción del sistema político soviético, a la geografía del país, a las características de la población y al "gigantesco crecimiento de la economía y de la cultura de la Unión Soviética respecto a la Rusia prerrevolucionaria”. Mapas mecánicos e iluminados, rodeados de maquetas de aviones comerciales a escala real, mostraban la expansión de la electrificación e industrial del país, mientras unas fotos recordaban el viaje de Khrushchev a Estados Unidos en septiembre de 1959.

La parte de la exposición dedicada a la técnica era inmensa, con más de 6000 artefactos presentados, y se mostraban "maquinas herramientas para el corte de metales, maquinaria para la construcción de carreteras, tractores, camiones de transportes, un camión para la perforación petrolífera, motos, motonetas y otros ejemplos de la industria nacional de construcción de maquinaria, que tenían interés desde el punto de vista comercial". Para facilitar la comprensión del uso de la maquinaria, los curadores soviéticos habían acompañado las unidades y las maquetas con proyecciones de películas que las mostraban en movimiento y más de 200 
altoparlantes y auriculares con contenido didáctico en español ofrecían otra herramienta importante para explicar el funcionamiento de las máquinas.

De gran interés para el público había resultado el pabellón sobre las hazañas de la exploración espacial soviética, que reproducía a escala natural satélites artificiales, instrumentos científicos lanzados hacia la Luna y los últimos avances en términos de misiles. Según Shelnov, desde la mañana temprano hasta el cierre diario: "[...] los estands con los satélites estaban rodeados de una multitud numerosa que escuchaba con gran atención las explicaciones emitidas por medio del micrófono por la voz registrada mecánicamente. Los mexicanos estaban simplemente asombrados con las creaciones del hombre".

Otra parte importante de la exposición, y de gran éxito en términos de público, había sido la sección dedicada a las principales aplicaciones pacíficas de la energía nuclear, que exhibía artefactos como reactores nucleares, aceleradoras de partículas, maquinas termonucleares y el buque rompehielos Lenin. ${ }^{45}$

Sería imposible enumerar aquí todas las secciones de la exposición con importancia y que atrajeron gran atención por parte del público y de los especialistas mexicanos. Lo que sí es necesario subrayar es que la exposición había significado un esfuerzo importante para la URSS, logrando ofrecer a México y a América Latina una imagen fuerte y convincente de la modernidad soviética, como destacaba el embajador soviético en México, Vladimir Bazykin, en una

${ }^{45}$ RGAE, Fond 635, Opis. 1, Delo. 392, “A. Shelnov, Reporte sobre el trabajo de la Exposición Soviética en México Año 1959”, sin fecha, aprox. enero de 1960, pp. 1-12. 
carta a A. Gromyko, ministro de asuntos exteriores de la URSS: "la exposición tuvo gran éxito [...] y, en buena medida, logró socavar años de propaganda antisoviética, mostrando lo que en realidad es la URSS”. El informe de Bazykin subrayaba también la importancia de la presencia de Mikoyán en México, la cálida recepción que le habían dado las autoridades mexicanas y la voluntad de López Mateos de visitar la URSS entre abril y mayo de 1961:

La visita a México del camarada A. I. Mikoyán para inaugurar la exposición, a nombre del gobierno soviético, tuvo gran importancia política y contribuyó a fortalecer nuestra posición en México. El camarada Mikoyán fue recibido y despedido en el aeropuerto por un número mayor de miembros del gabinete que el primer Ministro japonés Kisi quien recientemente estuvo de visita oficial en México. Para su traslado por el país, el presidente López Mateos puso a disposición de A. I. Mikoyán el avión oficial. Estos gestos de amistad por parte del presidente no habían ocurrido durante las visitas de otros huéspedes distinguidos, incluyendo jefes de gobierno y de estado. En principio, el presidente López Mateos aceptó la invitación del gobierno soviético para visitar la URSS. Tiene la intención de efectuar la visita a la URSS en abril-mayo de 1961.

Además, glosaba Bazykin, los dos países habían comenzado a dialogar sobre la posible firma de un tratado comercial bilateral que habría permitido sentar sobre una base más sólida las incipientes relaciones comerciales entre los dos países. ${ }^{46}$ Para los soviéticos la ampliación de los lazos comerciales

46 AVP RF, Fond 110, Sin Inventario, Sin Exp., Material informativo, "V. Bazykin. Sobre las relaciones mexicano soviéticas. "Camarada A.A. 
representaba, de hecho, una herramienta utilizada desde la segunda mitad de los años cincuenta en contextos del Tercer Mundo, como África occidental, donde la influencia de Moscú era lábil y la dependencia de Occidente, fuerte. ${ }^{47}$ De alguna forma, el aumento de los intercambios en términos ventajosos para los países del Tercer Mundo constituía un paso previo al establecimiento de un mayor nivel de cooperación económica dirigida hacia el desarrollo industrial.

Una parte del optimismo que se puede apreciar en el análisis de Bazykin era compartido también por algunas de las autoridades mexicanas. Ricardo J. Zevada, director general del Banco Nacional de Comercio Exterior y gran sostenedor de la necesidad de diversificación del comercio mexicano, en una conversación mantenida al final de noviembre con el jefe del Departamento de América Latina del Ministerio de Comercio Exterior de la URSS, A. P. Malkov, afirmaba que "con vuestra exhibición habéis logrado mucho para acercar al consumidor a los productos soviéticos, y en romper la actitud sospechosa del consumidor mexicano respecto a los productos soviéticos que se había formado aquí en años". Sin embargo, la interpretación de Zevada era más matizada que las de los soviéticos y acompañada del realismo de un alto funcionario que conocía en profundidad la realidad política y económica de su país. "En 10-15 días", glosaba el director del Banco de Comercio Exterior, no se cambia nada significativo, para esto "hace falta tiempo y lucha". ${ }^{48}$

Gromyko Acerca de las relaciones mexicano-soviéticas”, No. 516/OCA, 3 de agosto de 1960, p. 23.

${ }^{47}$ Iandolo, "The rise and fall", pp. 689-691.

${ }^{48}$ RGAE, Fond 413. Opis 13. Delo, 8510, pp. 63-68, "Memorandum de la Conversación del Jefe del Departamento de América Latina del 
Todavía más cautelosa era la interpretación que daban los estadounidenses del resultado obtenido por la exposición y de cuánto se había logrado por medio de los encuentros que Mikoyán había mantenido con las autoridades soviéticas. En un informe enviado a Roy Rubottom, funcionario de la oficina de asuntos latinoamericanos del Departamento de Estado, Harry Turkel, especialista en asuntos eurasiáticos, comentaba que durante su encuentro con las autoridades mexicanas Mikoyán había ofrecido una línea de crédito de 100000000 de dólares para inversiones en el sector petrolero que, como es notorio, desde 1938 se encontraba en manos del Estado mexicano. Según Turkel, esta no era la primera vez que los rusos ofrecían créditos a los mexicanos, añadiendo que en los últimos "dos años ha habido dos o tres ofertas similares”, todas rechazadas por México. Para Turkel, entonces, se podía afirmar que "Mikoyán no ha logrado gran cosa en el frente económico en México”. El experto de Rusia y Asia concluía diciendo que México, al tener líneas de crédito abiertas con instituciones bilaterales estadounidenses, como la Export/Import Bank, no se encontraba en una situación de emergencia y que, a menos de un decidido empeoramiento en la posición económica de México, “era improbable un aumento significativo de las relaciones comerciales mexicanas con la URSS”. ${ }^{49}$

Ministerio de Comercio Exterior (MFT) de la URSS, Camarada A.P. Malkov, con el Gobernador del Banco Nacional de Comercio Exterior en México, Señor Ricardo Jose Zevada del 23 de noviembre de este año", aprox. nov.-dic. de 1959.

49 NARA RG59, Bureau of Inter-American Affairs, Office of InterAmerican Regional Economic Affairs, Country and Subject File, Box 1 Arc ID2321376, "Your Request Re Information on German Trade 
En el arco de pocos años, como veremos, el optimismo generado por el éxito de la exposición soviética dejaría paso al velado pesimismo insinuado por Zevada y a la cautela de los diplomáticos estadounidenses.

\section{LOS TRACTORES DE LA DISCORDIA}

Como había destacado el embajador Bazykin en su informe de agosto de 1960, a la conclusión de la exposición había seguido una cerrada serie de viajes oficiales de delegaciones mexicanas a la URSS y viceversa y, todavía más importante, los dos países habían comenzado a dialogar sobre la forma de agilizar el comercio bilateral por medio de un tratado. Sin embargo, como había dejado claro Zevada en su conversación con los funcionarios soviéticos, concretar el clima de optimismo creado por la exposición en medidas de acercamiento concreto entre las URSS y México no iba a ser un asunto sencillo.

Durante un encuentro entre el presidente López Mateos y el secretario de asuntos exteriores Manuel Tello con los miembros de la delegación de buena voluntad soviética que había visitado México en el verano de 1961, se podía seguir apreciando cierto optimismo, aunque ya emergían algunos elementos de preocupación por la parte soviética. Según los soviéticos, a lo largo de una conversación definida como "cálida y amistosa” López Mateos había subrayado "la coincidencia de puntos de vista entre México y la Unión Soviética en relación con varios asuntos internacionales

Mission to Latin America and Mikoyán's visit to México”, 15 de diciembre de 1959. 
de importancia”. El presidente mexicano había recordado que, en su última intervención en la ONU, se había manifestado "por el desarme general y completo, por la distensión, el fortalecimiento del entendimiento mutuo entre todos los pueblos del mundo. La posición de México en estos asuntos es firme e inquebrantable", había concluido el presidente. Es probable que, sobre temas como la descolonización, la distensión y la construcción de mecanismos de cooperación entre las naciones del mundo, la URSS y México tuvieran, en el verano de 1961, cierta coincidencia de puntos de vista. Sin embargo, al momento de concretar pasos efectivos para consolidar el acercamiento bilateral, tanto el presidente López Mateos como el secretario de Relaciones Exteriores habían mostrado más de una reticencia. El presidente mexicano, aduciendo la necesidad de supervisar las elecciones municipales y del Congreso, había dejado claro que no habría viajado, como antes se había especulado, a la URSS y que, en su lugar, habría enviado el secretario de Industria y Comercio, Raúl Salinas Lozano.

La conversación con el secretario Tello había sido más concreta e indicativa de los problemas a que se enfrentaba la ampliación de las relaciones comerciales entre los dos países:

Manuel Tello declaró que el gobierno mexicano aplaude la ampliación de los contactos entre los hombres públicos de México y la URSS [...] M. Tello señaló que el futuro desarrollo de las relaciones puede ser posible no sólo en el ámbito de la cultura, sino también en el del comercio. Sin embargo, precisó que en México casi todo el comercio se encuentra concentrado en manos de compañías privadas y que el gobierno no tiene muchas posibilidades de influir en la política comercial. 
La conclusión a la cual había llegado la delegación soviética después de estos dos encuentros era que:

[...] el gobierno mexicano en general está interesado en mantener relaciones normales con la Unión Soviética y, gracias a la influencia de la opinión pública, está dispuesto a ampliarlas en cierta medida, sobre todo en la línea del intercambio cultural y sobre todo artístico. Respecto de las relaciones económicas y comerciales, en el corto plazo, tomando en consideración el predominio del capital norteamericano en la economía del país, de hecho no existen perspectivas favorables para un desarrollo apreciable. ${ }^{50}$

El optimismo generado por la exposición y, en general, el entusiasmo producido por las nuevas políticas de Khrushchev habían impedido a los soviéticos ver los obstáculos tanto de orden técnico como político que limitaban un progreso sustancial de las relaciones bilaterales con México de forma rápida. Política y logística, de hecho, podían llegar a dificultar hasta la simple venta de unos 75 tractores soviéticos a México, mostrando todas las dificultades y los límites de los intentos de acercamiento entre los dos países.

En octubre de 1958, la empresa soviética estatal Aavtoexport EEA, encargada de exportar máquinas de distintos tipos, había firmado un acuerdo para la venta de 75 tractores modelo DT-54 y maquinaria varia agrícola a México. ${ }^{51}$

${ }^{50}$ RGAE, D.D. Degtyar (1904-1982), Personal Collection, Fond 645, Opis 1, Delo 31, "Reportes sobre el viaje a América Latina", Reporte sobre el viaje de Buena Voluntad de la Delegación Soviética a los Países Latinoamericanos, sin fecha, aprox. 1961-1962.

${ }^{51}$ RGAE, Fond 413. Opis. 13. Delo 8510, "Reporte del camarada K. D. Tikhomirov y B. M. Streltsov sobre el viaje a Ciudad Obregón y el 
La prensa mexicana había especulado sobre la compra de los tractores, atribuyendo la iniciativa a los buenos oficios del expresidente Lázaro Cárdenas quien, según distintas versiones, había negociado su adquisición directamente con Moscú. ${ }^{52}$ Por lo que se puede reconstruir a partir de la documentación soviética, los tractores estaban originalmente destinados a un grupo de ejidos de la Comarca Lagunera y se estaba negociando otra posible venta a la Alianza de Sociedades Locales Colectivas Maximiliano López del Valle del Yaqui, Sonora (en los documentos rusos la "Alianza Maximilian”). Tanto la Alianza como el grupo de ejidos de la Comarca Lagunera representaban uniones ejidatarias algodoneras particularmente reivindicativas, la primera liderada por Ramón Danzós Palomino y la segunda por Arturo Orona, ambos pertenecientes al Partido Comunista Mexicano. ${ }^{53}$ Por lo menos desde la mitad de la década, como lo ha estudiado Luis Aboites Aguilar, estos grupos habían pugnado para la diversificación del mercado del algodón, monopolizado por la empresa estadounidense Anderson y Clayton, que lograba imponer bajos precios para la compra del

puerto de Guaymas, estado de Sonora, 14 al 17 de mayo, 1959”, 21 de mayo de 1959, pp. 30-34; RGAE, Fond 413, Opis 13, Delo 8510, "Memorandum de la Conversación con el ministro de agricultura Ing. Julián Rodríguez Adame del 31 de julio 1959”, Ref. \# 368, 4 de agosto de 1959, pp. 49-51; RGAE, Fond 413, Opis 13, Delo 8510, "Memorándum de la Conversación entre el Camarada K. D. Tikhomirov, Consejero Comercial de la Embajada de la URSS en México, con los gerentes de la empresa 'De Swaan', S. A., Sheyman y De Swaan, que tuvo lugar los días 7 y 9 de Febrero de 1959", 20 de febrero de 1959, pp. 4-5.

52 "Poco Comercio con la URSS", El Porvenir (4 abr. 1959), p. 1; “Mirador", Jueves de Excelsior (21 mayo 1959), p. 6.

${ }^{53}$ Trevizo, Rural Protest, p. 106. 
producto. ${ }^{54}$ Para evitar estas prácticas, por ejemplo, la unión había propuesto vender el algodón mexicano en los mercados del bloque socialista, en especial en Polonia y Checoslovaquia, a cambio de maquinaria soviética de varios tipos. ${ }^{55}$ Además, tanto la Alianza como el grupo de Orona habían mantenido una postura de sindicalismo independiente $y$, desde el final de la década, habían abandonado a la oficialista Confederación Nacional Campesina (CNC), acercándose a las posiciones del Movimiento de Liberación Nacional fundado por Lázaro Cárdenas y contribuyendo a la fundación de la Central Campesina Independiente de la cual ambos fueron secretarios. ${ }^{56}$ Las conexiones políticas de los susodichos ejidos podrían confirmar de forma indirecta las notas de periódicos como El Porvenir o Jueves de Excelsior, que atribuían a Cárdenas un papel central en la negociación que había llevado a la adquisición de los tractores.

Moscú, como fue previsto por el contrato firmado el 25 de octubre de 1958, efectivamente había enviado 75 tractores y otras maquinarias agrícolas a México. Sin embargo, en julio de 1959, a cuatro meses y medio de su llegada, éstos se encontraban todavía sin entregar, almacenados en la zona aduanal del puerto de Tampico, alimentando todo tipo de sospechas en la prensa mexicana. Un artículo de Pedro Vazquez Cisneros en Jueves de Excelsior, por ejemplo, reportaba todo tipo de leyendas sobre la maquinaria soviética de Tampico, desde su conversión en chatarra por haber sido dejada

\footnotetext{
54 Aboites Aguilar, El norte entre algodones, pp. 154-155.

55 Aвоites Aguilar, El norte entre algodones, p. 154.

${ }^{56}$ Stavenhagen, Between Underdevelopment, p. 145; Trevizo, Rural Protest, p. 106.
} 
a la intemperie, hasta su naturaleza obsoleta al ser los tractores viejos, equivalentes a los que se utilizaban en el campo mexicano hace más de 30 años. Finalmente, la nota volvía a plantear el problema del papel de Cárdenas en la negociación y adquisición de la maquinaria de Moscú. ${ }^{57}$

En febrero de 1959, antes de la llegada de los tractores a México, el encargado de asuntos comerciales de la embajada soviética en México, K. D. Tikhomirov, acompañado por dos ingenieros de la URSS, había mantenido una poco esperanzadora reunión con la compañía mexicana responsable de la importación de la maquinaria, De Swaan, S. A., con Arturo Orona, a quien la documentación soviética describe como el representante de la Unión Ejidal de la Provincia de Cuauhtémoc, y con V. López, a quien los documentos identifican como consejero del Banco Ejidal. ${ }^{58}$ La reunión había evidenciado una larga serie de problemas logísticos para la compra de la maquinaria agrícola soviética. En el documento, Tikhomirov manifestaba su preocupación a los representantes de De Swaan porque el Banco Ejidal no había emitido un certificado de compromiso de pago. En cambio, en la carta entregada a la empresa soviética Avtoexport se hacía depender el desembolso de los resultados de las labores agrícolas de las unidades ejidales. Además, a pesar de la falta de un compromiso oficial respecto al pago de los tractores, el contrato preveía una transferencia parcial de la propiedad de los mismos a la compañía De Swaan. Resumiendo, los representantes de la empresa importadora mexicana pretendían recibir la maquinaria sin pagarla de inmediato y sin ofrecer una garantía de

\footnotetext{
57 “Mirador", Jueves de Excelsior (21 mayo 1959), p. 6.

${ }^{58}$ Stavenhagen, Between Underdevelopment, p. 145.
} 
pago futuro, obteniendo además la transferencia de una parte de su propiedad.

También habría que subrayar cómo durante la negociación De Swaan había ofrecido a los soviéticos resolver el problema del pago mediante un trueque, algodón mexicano a cambio de maquinaria soviética, una opción utilizada con éxito por la URSS en otras partes del Tercer Mundo para ampliar su influencia comercial. Por razones que no son fáciles de entender, los diplomáticos soviéticos habían rechazado de forma algo desdeñosa la propuesta respondiendo que "Avtoexport EEA no tenía registrada al momento ninguna solicitud de adquisición de algodón para sus clientes".

Después de un largo debate, donde Arturo Orona había apoyado en gran medida las posiciones soviéticas y López había permanecido callado, se había logrado un compromiso con base en el cual Moscú, aun sin una garantía del Banco Ejidal, mantenía una reserva de dominio sobre los tractores que le permitía recuperar la mercancía en caso de no realizarse el pago total. ${ }^{59}$ Aunque la cuestión de la carta compromiso no se resolvió durante dicha reunión, otra documentación soviética indica que, para la primavera, la empresa soviética de exportación había logrado el compromiso oficial del Banco Ejidal para el pago de los tractores a entregarse en la Comarca Lagunera.

Este primer encuentro había mostrado varios problemas en la realización de las transacciones comerciales entre los

${ }^{59}$ RGAE, Fond 413. Opis 13. Delo 8510, "Memorándum de la Conversación entre el Camarada K. D. Tikhomirov, Consejero Comercial de la Embajada de la URSS en México, con los gerentes de la empresa De Swaan, S. A., Sheyman y De Swaan, que tuvo lugar los días 7 y 9 de Febrero de 1959”, 20 de febrero de 1959, pp. 4-5. 
dos países. En primer lugar, en la parte mexicana, se hacía evidente la falta de un claro apoyo por parte del Banco Ejidal, que en teoría era la institución pública encargada de ofrecer a las unidades ejidales el apoyo financiero para la compra de los tractores. En cambio, desde el lado soviético, emergía la ausencia de mecanismos e instituciones financieras que coadyuvaran en los intentos de ampliar el comercio con México. Es cierto que los soviéticos estaban dispuestos a entregar los tractores a cambio de un simple compromiso de pago del Banco Ejidal. Sin embargo, una ofensiva comercial, parte de una más amplia estrategia política de acercamiento a América Latina, necesitaba de mayor planificación $\mathrm{y}$ de instrumentos financieros que ayudaran a hacer frente a situaciones problemáticas como la que se había creado con los ejidatarios mexicanos de la Comarca Lagunera. Esto sin contar que, durante la negociación, los diplomáticos de la URSS de forma muy rígida habían rechazado el mecanismo del trueque. Éste, como había ocurrido en otras áreas del Tercer Mundo, podía representar una herramienta de entrada muy poderosa en los mercados de los países en desarrollo, considerando el problema relacionado con los excedentes de productos primarios y la falta de capitales que éstos tenían.

La reunión de febrero y los problemas evidenciados en las negociaciones bilaterales anunciaban nubes todavía más grises. De hecho, como he destacado arriba, una vez llegados a Tampico (aproximadamente al final de marzo) los tractores se quedaron parados en las instalaciones portuarias por meses. En mayo de 1959, para intentar comprender los problemas de las realidades ejidales y, también, los factores que pudieran estar determinando el bloqueo de la maquinaria soviética en el puerto mexicano, Tikhomirov, acompañado 
por el ingeniero Streltsov, realizó una expedición en la región algodonera de Sonora. Aquí, guiados por Ramón Danzós Palomino (Donsos, en ruso en el documento original soviético), los soviéticos se dieron cuenta de los múltiples problemas a los cuales se enfrentaban las unidades productivas ejidales en la región. ${ }^{60}$ En su reporte, Tikhomirov destacaba la presencia de 85 ejidos, definidos por los soviéticos como cooperativas, de los cuales entre 8 y 10 eran colectivos y los restantes, individuales. La Alianza, constituida por un presidente externo y los representantes de cada cooperativa, era, según el diagnóstico soviético, la encargada de obtener créditos y el abastecimiento de agua para la irrigación de los campos y, en Fgeneral, de lidiar y resolver todos los problemas logísticos de las cooperativas. El reporte de Tikhomirov revelaba que, en cuanto a la compra de tractores, las cooperativas colectivas, definidas por al attaché comercial como la "forma más progresiva de cooperación entre campesinos mexicanos", tenían que proceder de forma individual. Al mismo tiempo, el informe subrayaba que los ejidos, incluyendo a los colectivos, tenían una maquinaria escasa y anticuada y, al tener también una capitalización casi nula, dependían fuertemente del crédito concedido por el Banco Ejidal para la adquisición de nueva. Según los datos proporcionados por los ejidatarios a los diplomáticos y técnicos soviéticos, sólo $20 \%$ de las tierras eran trabajadas por maquinaria de propiedad, mientras el restante $80 \%$ con maquinaria alquilada a empresas estadounidenses y mexicanas. Los ejidos

${ }^{60}$ RGAE, Fond 413. Op. 13. Delo 8510, "Reporte del camarada K. D. Tikhomirov y B. M. Streltsov sobre el viaje a Ciudad Obregón y el puerto de Guaymas, estado de Sonora, 14-17 de mayo de 1959”, 21 de mayo de 1959, pp. 30-34. 
pagaban aproximadamente 80 pesos mexicanos a las compañías por la renta, que incluía la conducción y la gasolina de los tractores. Al tener escaso capital, estos montos se pagaban mediante créditos concedidos por el Banco Ejidal a un interés anual de 7-8\%. Además, el Banco Ejidal se encargaba también de comprar directamente los fertilizantes, cobrando una comisión de $5 \%$ a los ejidos. Según los ejidatarios, las compras realizadas por el Banco Ejidal no respondían a criterios de eficiencia presupuestal sino más bien financiera, una afirmación que los soviéticos juzgaban acertada.

En relación con la cuestión de los tractores, durante su pesquisa Tikhomirov había podido averiguar que en el estado de Sonora estos eran vendidos exclusivamente por compañías estadounidenses y canadienses como Case, Caterpillar, Ford, John Deere, Oliver, Massy Harry, etc., y que no había rastro de empresas de otros países. Estas compañías tenían una oficina de representación en muchas ciudades del estado y la maquinaria era expuesta en salones de exposición bien equipados y provistos de todo tipo de piezas de refacción. En general, las empresas en cuestión ofrecían los primeros 2 o 3 tractores sin necesidad de garantías de pago mientras que, para compras de lotes más grandes, exigían cartas compromiso por parte de los dos institutos de crédito estatales, el Banco Ejidal y el Banco de Crédito Agrícola. Por lo general el pago se efectuaba en un plazo de cuatro años con un interés de $4 \%$. Finalmente, al examinar la cuestión de la concesión de los créditos, los enviados soviéticos descubrían la presencia de factores políticos importantes que limitaban la posible expansión del comercio soviético con el estado y con el país. Sondeados por los soviéticos acerca de la posible compra de tractores procedentes de la URSS, los 
representantes ejidales admitían no estar en condiciones de realizar ni siquiera un primer pago de $20 \%$ o incluso de $10 \%$ del importe porque, al ser mercancía soviética, el Banco Ejidal de la región rechazaba ofrecer el crédito a las cooperativas.

En julio del mismo año, a tan sólo unos pocos meses de la visita realizada en Sonora, un encuentro entre Tikhomirov y el embajador Bazykin con el secretario de Agricultura y Ganadería de México, Julián Rodríguez Adame, habría de confirmar a los soviéticos lo que los ejidatarios habían explicado acerca de los factores que obstaculizaban la expansión del comercio bilateral y, también, la salida de los tractores de Tampico hacia la Comarca Lagunera. Durante el encuentro, los soviéticos cuestionaron al secretario Adame sobre las razones que mantenían desde hacía cuatro meses y medio a la maquinaria soviética parada en el puerto, añadiendo que poseían una carta compromiso del Banco Ejidal para el pago de la mercancía. El punto era, añadían los diplomáticos de la URSS, que sin entregar la maquinaria a los ejidos de destino no se podía empezar a solicitar y ejecutar el pago. El secretario contestó diciendo que al día siguiente se encargaría del asunto pero que, sin embargo, podía adelantar que se había decidido entregar los tractores a unas zonas distintas de las originalmente planeadas. Tikhomirov y Bazykin contestaron diciendo que habría sido mejor concentrar los tractores en zonas limítrofes para garantizar un uso más eficiente de la maquinaria, y facilitar su manutención y la distribución de las piezas de repuesto. Adame contestó de modo tajante que los tractores se enviarían a las zonas que más los necesitaban. Además, añadió que el retraso en su entrega se debía a una razón de orden político. Los tractores no se habían entregado a los ejidos de La Laguna porque 
estos eran dirigidos por comunistas y recomendó que, en un futuro, los soviéticos condujeran sus transacciones sobre la base de razones "puramente comerciales" y no para que los tractores fueran utilizados "por ciertas personas en ciertas regiones". 61

Las fuentes soviéticas disponibles no permiten documentar de forma concluyente que la entrega de los tractores a ejidos vinculados con el PCM y un sindicalismo más independiente haya respondido a una estrategia precisa de la URSS, planeada con la ayuda de Cárdenas, para favorecer a los sectores que los propios soviéticos definían como los más progresistas del país. Sin embargo, el contenido de las notas de El Porvenir y de Jueves de Excelsior, que atribuían a Cárdenas un papel central en la negociación de los tractores, aunado a la documentación soviética, parecen sugerir indirectamente que la operación había tenido, además de una naturaleza comercial, una connotación ideológica definida. Es decir, la entrega de los tractores a los campesinos de la Comarca Lagunera mostraría que los soviéticos estaban interesados en que los tractores fueran destinados a ejidos, unidades productivas parecidas a los koljoses, regidos por fuerzas políticas más afines a Moscú. Si nos atenemos a las palabras del secretario Rodríguez Adame, el nexo político ideológico de la operación comercial habría estado, de hecho, entre las causas de su casi fracaso.

Este episodio muestra una amplia gama de problemáticas político ideológicas que podían dificultar el aterrizaje del proceso de acercamiento bilateral. Por un lado, la permanencia

61 RGAE, Fond 413. Opis 13. Delo 8510, "Memorandum de la Conversación con el ministro de agricultura Ing. Julián Rodríguez Adame del 31 de Julio 1959”, Ref. \# 368, 4 de agosto de 1959, pp. 49-51. 
por más de 11 meses de los tractores soviéticos en Tampico evidencia cómo las propias divisiones internas del establishment político mexicano podían obstaculizar el establecimiento de relaciones más estrechas entre la URSS y México. Claramente, un sector de la élite política del país se oponía a que los tractores soviéticos acabaran en ejidos con una caracterización política bien definida, es decir, comunista, o ligados a la figura de Cárdenas, evidenciando la presencia de una fuerte divergencia ideológica en el seno de la propia clase dirigente del país. El incuestionable anticomunismo de algunos sectores políticos y gubernamentales mexicanos, ilustrado por este episodio, no podía más que representar un freno interno a la ampliación de las relaciones entre los dos países. Por otro lado, el incidente muestra también cierta ingenuidad soviética al llevar a cabo una operación comercial que minusvaloraba el componente de conflictividad ideológica del país. El haber pensado que la entrega de unos tractores soviéticos a unos ejidos caracterizados ideológicamente pudiera darse sin problemas mostraba la poca capacidad de valoración que Moscú tenía del contexto político mexicano, lo que debilitaba la efectividad de su estrategia de acercamiento a México.

Además de las dificultades políticas, el episodio permite identificar a nivel micro las problemáticas logísticas que en un escenario de fuerte dependencia mexicana del comercio con Washington reducía las capacidades de maniobras de Moscú. La dependencia mexicana del comercio con Estados Unidos, que en este caso se manifestaba por la fuerte presencia de compañías estadounidenses productoras de maquinaria agrícola, con capacidad financiera apoyada también por instituciones de crédito nacionales, dificultaba la entrada de equipo soviético. Además, como hemos visto, la maquinaria 
soviética no estaba apoyada por instrumentos financieros proporcionados por Moscú que facilitaran su integración en un mercado acostumbrado de forma inercial a los productos estadounidenses.

En otra conversación que el editor de la revista del Banco Nacional de Comercio Exterior, Arturo Perera Mena, mantuvo años más tarde, en julio de 1962, con A. Pavlenko, el corresponsal para México de la agencia estatal Soviética de información TASs, se pueden apreciar las dinámicas de dependencia que hemos podido observar a nivel micro, que limitaban la expansión de relaciones comerciales bilaterales más sólidas. De alguna forma, a pesar del tiempo transcurrido del episodio de los tractores, las mismas situaciones seguían generando fuertes dificultades para acelerar el proceso de acercamiento económico comercial entre los dos países. Perera Mena confirmaba el fuerte interés en ampliar las relaciones entre los dos países por la parte mexicana y, sin embargo, recordaba a su interlocutor que la razón principal que obstaculizaba este proceso era, según él, “los Estados Unidos”. Según Perera Mena, las empresas estadounidenses vendían sus productos a México a plazos y sobre la base de créditos que colocaban al país latinoamericano en una posición de dependencia. De hecho, recordaba Perera Mena, el crédito podía interrumpirse en cualquier momento y, además, añadía que el país dependía en el nivel macroeconómico del apoyo y los préstamos del Tesoro Americano y de los bancos privados del país. Perera Mena explicaba que, por ejemplo, la firma de un tratado comercial entre los dos países podía causar una reacción “malevolente por parte de Estados Unidos” y que por esto era aconsejable una evolución más cautelosa de las relaciones entre México y la URSS que no despertara la ira del vecino. 
Las reflexiones de Perera Mena y las palabras del secretario Rodríguez Adame muestran que logística, dependencia y polarización ideológica dentro del propio establishment político mexicano explican la dificultad que, como hemos visto, podía plantear incluso la venta de una pequeña partida de tractores soviéticos a México. Si a esto añadimos la ingenuidad que los soviéticos habían mostrado al llevar a cabo la venta y entrega de tractores, logramos una imagen muy precisa de los factores que obstaculizaron, durante la presidencia de López Mateos, un mayor y efectivo acercamiento entre los dos países.

En junio de 1964, a pocos meses de finalizar la presidencia de López Mateos, una delegación mexicana encabezada por el propio Zevada visitaba la URSS para familiarizarse con la industria soviética y, según dejaba entender el director general de la Banca de Comercio Exterior, estudiar finalmente el posible establecimiento de un tratado comercial permanente entre los dos países. La delegación estaba integrada por representantes de algunas de las instituciones más importantes del país, incluidos el Banco de México, Pemex, la Secretaría de Relaciones Exteriores, la de Industria y Comercio y el representante del consorcio industrial de Ciudad Sahagún, entre otros. ${ }^{62} \mathrm{~A}$ pesar de las expectativas generadas por el propio Zevada, el mayor logro alcanzado por la delegación económica mexicana fue un acuerdo para la venta de 10 turbinas de extracción para pozos petrolíferos. ${ }^{63}$ En noviembre

${ }^{62}$ AVP RF, Fond 110, Opis 24, Delo 53, "Letter from Ricardo Zevada and the Mexican delegation and other materials from the Mexican delegation", 21 de mayo de 1964; "Telegram about the visit of the Mexican delegation in the USSR", 23 de junio de 1964.

${ }^{63}$ RGAE, Fond 413. Opis 31. Delo 28, "Para el viceministro camarada 
del mismo año una delegación de expertos petroleros, liderada por Nikolai Baibakov, visitó México para estallar desde el punto de vista técnico el acuerdo y su implementación. Sin embargo, para abril de 1965 las perforadoras todavía no se habían instalado y el nuevo presidente de México, Gustavo Díaz Ordaz, a pesar de declararse en favor de una ampliación de las relaciones con la URSS, negaba a los especialistas soviéticos las visas necesarias para entrar en el país e instalar la maquinaria petrolera. ${ }^{64}$ La historia de los tractores se repetía, ahora con el todavía más delicado sector del petróleo mexicano. Para que México pudiera superar las líneas de contención de distintos tipos que se presentaban en la década de los sesenta, y la URSS vencer las resistencias mexicanas, hubo que esperar a los años setenta, cuando el nuevo contexto de distensión bipolar, conocido como détente, permitió que fructificaran los contactos construidos entre 1958 y 1964.

\section{CONCLUSIONES}

Las expectativas generadas por el viaje llevado a cabo por Mikoyán a México en noviembre de 1959, en el marco de la inauguración de la exposición científica y técnica soviéti$\mathrm{ca}$, no llegaron a cumplirse. Aunque gracias a su presencia, contactos y conversaciones México y la URSS ensancharon sensiblemente el perímetro de las relaciones bilaterales, la firma de un acuerdo comercial entre los dos países, el objetivo central de la estrategia soviética, no se pudo dar durante

I. F. Semichastnov, para el jefe de la división de protocolo camarada I. I. Dokuchaev", 23 de junio de 1964, pp. 26-27.

${ }^{64}$ AVP RF, Fond. 110. Opis. 25. Delo 54, "Mexico (Una nota corta)", 2 de mayo de 1965. 
el mandato de López Mateos. Además, como hemos visto, a lo largo del sexenio, México rechazó en más de una ocasión una línea de crédito soviética para el desarrollo de una de sus principales industrias estatales, Pemex. Hasta la venta de unos pocos tractores soviéticos al país latinoamericano se tornó compleja, mostrando todos los límites del proceso de acercamiento entre los dos países.

La documentación existente no permite apreciar la presencia de presiones directas estadounidenses sobre México para obstaculizar el acercamiento con la URSS. Lo que sí ha podido revelar el presente artículo es que la propia configuración político económica de las relaciones con Estados Unidos en el contexto de enfrentamiento bipolar y la polarización interna mexicana representaron el dique natural más poderoso para evitar una mayor aproximación entre México y la URSS. De alguna forma, las mismas estructuras político económicas bilaterales que el presidente López Mateos intentaba superar reducían las posibilidades de poner en marcha una estrategia de diversificación que incluyera a la URSS. La fuerte integración financiero económica que México y Washington habían alcanzado a mitad de los años sesenta tornaba muy complejo un proceso de diversificación comercial. Como subrayaba Harry Turkel en su informe a Rubottom, a nivel macro, la fuerte estabilidad mexicana dependía también del apoyo que Washington ofrecía por medio de líneas de crédito preferenciales, como las del Export/Import Bank al país. Ampliar relaciones con el principal competidor geopolítico de Estados Unidos, como había afirmado Perera Mena, podía suponer un riesgo para el acceso a estos recursos. Por otro lado, a nivel micro, el mercado mexicano estaba muy acostumbrado a la presencia de 
productos estadounidenses, lo cual hacía difícil para la URSS poner en marcha una estrategia de sustitución de maquinaria estadounidense por soviética.

Este dique natural se vio reforzado por la falta de planificación soviética y la rigidez que en algunas ocasiones mostraron los dirigentes soviéticos. Como se ha visto, la URSS ofrecía sus productos sin la presencia de mecanismos financieros ventajosos, en particular para un mercado potencialmente hostil. Además, la rigidez de los diplomáticos soviéticos le impedía incluso aprovecharse de mecanismos, como el trueque de maquinaria por productos primarios, que la URSS utilizaba en otros contextos y que los teóricos soviéticos tenían en su aljaba. Finalmente, como hemos visto, dificultades de naturaleza político ideológica, propias del contexto político interno mexicano, aunadas a cierta ingenuidad soviética, podían dificultar hasta la venta de una partida de tractores y poner en riesgo la estrategia de acercamiento.

A pesar de los problemas encontrados en esta etapa, se puede argumentar también que sin los esfuerzos bilaterales y el tanteo de los límites y retos que se dieron entre el final de la década de los años cincuenta y la mitad de la de 1960, el mayor acercamiento de los años setenta habría sido imposible. En el fondo, los temas que fueron tratados sin éxito durante la presidencia de López Mateos, y en especial el acuerdo comercial con el bloque socialista, llegaron a concretarse en mayor medida durante la década de 1970.

De alguna forma, como este artículo muestra, a pesar de la poca atención recibida, la década de los sesenta esconde algunas de las encrucijadas todavía poco estudiadas y, sin embargo, más importantes para la reconstrucción de la evolución histórica del México contemporáneo. 


\section{SIGLAS Y REFERENCIAS}

AGE, SRE Archivo Genaro Estrada, Secretaría de Relaciones Exteriores, México.

AVP RF Archivo de la Política Exterior de la Federación Rusa, Moscú, Rusia.

CIA-CREST Central Intelligence Agency CIA Records Search Tool, National Archives at College Park, College Park, MD, Estados Unidos.

NARA, National Archives at College Park, College Park, MD, Estados Unidos.

RAN Archivo Histórico de la Academia de la Ciencia de Moscú, Rusia.

RGAE Archivo del Estado Ruso de Economía, Moscú, Rusia.

Aboites Aguilar, Luis

El norte entre algodones: población, trabajo agricola y optimismo en México, 1930-1970, México, El Colegio de México, 2013.

Bethell, Leslie y Ian Roxborough

"The Impact of the Cold War on Latin America", en LefFler y Painter (eds.), 2005, pp. 299-316.

Cárdenas, Enrique

“La economía en el dilatado siglo xx, 1929-2009”, en Kuntz FICKER (coord.), 2010, pp. 503-547.

CÁrdenas, Héctor

Historia de las relaciones entre México y Rusia, México, Fondo de Cultura Económica, 1993.

Cárdenas, Lázaro y Alexander Sizonenko (comp.)

Relaciones mexicano-soviéticas 1917-1980, México, Secretaría de Relaciones Exteriores, Academia de la Ciencia de la URSS, 1981. 
Covarrubias, Ana

“Las relaciones México-Cuba, 1959-2010", en VegA, 2011, pp. 241-317.

Dosman, Edgar J.

The Life and Times of Raúl Prebisch, 1901-1986, Montreal, McGill-Queen’s University Press, 2010.

Engerman, David C.

"Learning from the East. Soviet Experts and India in the Era of Competitive Coexistence", en Comparative Studies of South Asia, Africa and the Middle East, 33, 2 (2013), pp. 227-238.

Fazio Vengoa, Hugo

"América Latina vista por los académicos soviéticos: preámbulo de las relaciones ruso-latinoamericanas", en Historia Crítica, 15 (1997), pp. 31-49.

Fitzgerald, E. Valpy y Rosemary Thorp (eds.)

Economic Doctrines in Latin America: Origins, Embedding and Evolution, Nueva York, Palgrave MacMillan, 2005.

Friedman, Jeremy

Shadow Cold War. The Sino-Soviet Competition for the Third World, Chapel Hill, University of North Carolina Press, 2015.

Getchell, Michelle Denise

"Revisiting the 1954 Coup in Guatemala: The Soviet Union, the United Nations and 'Hemispheric Solidarity'”, en Journal of Cold War Studies, 17: 2 (2015), pp. 73-102.

González Casanova, Pablo

La democracia en México, México, Era, 1967.

Graziosi, Andrea

L'URSS dal Trionfo al Declino. Storia dell'Unione Sovietica. 1945-1991, Bolonia, Il Mulino, 2008. 
Helleiner, Eric

"Reinterpreting Bretton Woods: International Development and the Neglected Origins of Embedded Liberalism", en Development and Change, 37: 5 (2006), pp. 943-967.

IANDolo, Alessandro

"The rise and fall of the 'Soviet Model of Development' in West Africa, 1957-1964”, en Cold War History, 12: 4 (2012), pp. 683-704.

Kalinovsky, Artemy M.

"Not Some British Colony in Africa: Khrushchev and The Politics of Modernization in Central Asia”, en Ab Imperio, 2 (2013), pp. 191-222.

Keller, Renata

Mexico's Cold War: Cuba, the United States, and the legacy of the Mexican Revolution, Nueva York, Cambridge University Press, 2015.

“A foreign policy for domestic consumption Mexico's Lukewarm Defense of Castro, 1959-1969", en Latin American Research Review, XLVII (2012), pp. 100-119.

Kuntz Ficker, Sandra (coord.)

Historia económica general de México. De la Colonia a nuestros días, México, El Colegio de México, 2010.

Leffler, Melvyn P. y David S. Painter (eds.)

The Origins of the Cold War: An International History, Nueva York, Routledge, 2005.

Loaeza, Soledad

Clases medias y política en México: la querella escolar, 19591963, México, El Colegio de México, 1988.

"Modernización autoritaria a la sombra de la superpotencia, 1944-1968”, en Nueva Historia General de México, México, El Colegio de México, 2010, pp. 653-698. 
Love, Joseph L.

“The Rise and Fall of Structuralism", en Fitzgerald y Thorp (eds.), 2005, pp. 157-181.

Meyer, Lorenzo

"La Guerra Fría en el mundo periférico: el caso del régimen autoritario mexicano. La utilidad del anticomunismo discreto”, en Spenser (coord.), 2004, pp. 95-118.

Miller, Nicola

Soviet relations with Latin America, 1959-1987, Cambridge, Cambridge University Press, 1989.

Nueva Historia General de México

Nueva Historia General de México, México, El Colegio de México, 2010.

OJeda, Mario

Alcances y límites de la política exterior de México, México, El Colegio de México, 2001.

Pellicer, Olga

México y la revolución cubana, México, El Colegio de México, 1972.

Pettinà, Vanni

“Adapting to the New World: Mexico's International Strategy of Economic Development at the Outset of the Cold War, 1946-1952”, en Culture and History, 4:1 (2015), pp. 1-16.

"Global Horizons: Mexico, the Third World, and the NonAligned Movement at the Time of the 1961 Belgrade Conference", en International History Review (2015), DOI: 10.1080/07075332.2015.1124906.

"Mexican-Soviet relations, 1958-1964: The Limits of Engagement”, en CwiHP e-Dossier, 65 (2015) https://www.wilsoncenter.org/publication/mexican-soviet-relations-1958-1964the-limits-engagement 
RupPrEcht, Tobias

"Socialist high modernity and global stagnation: a shared history of Brazil and the Soviet Union during the Cold War", en Journal of Global History, 6 (2011), pp. 505-528.

Soviet internationalism after Stalin: interaction and exchange between the USSR and Latin America during the Cold War, Cambridge, Cambridge University Press, 2015.

SÁnCHEZ-Sibony, Oscar

Red Globalization. The Political Economy of the Soviet Cold War from Stalin to Khrushchev, Nueva York, Cambridge University Press, 2014.

SEWELL, Bevan

"A perfect (free-market) world? Economics, the Eisenhower administration, and the Soviet economic offensive in Latin America”, en Diplomatic History, 32: 5 (2008), pp. 841-868.

Spenser, Daniela (coord.)

Espejos de la Guerra Fría: México, América Central y el Caribe, Mexico, Porrúa, 2004.

Stavenhagen, Rodolfo

Between Underdevelopment and Revolution: a Latin American Perspective, Nueva Delhi, Abhinav, 1981.

Torres, Blanca

"México en la estructura del comercio y la cooperación internacional de los países socialistas", en Foro Internacional, 13: 2 (1972), pp. 178-210.

México y el mundo: historia de sus relaciones exteriores, $t .7$, De la guerra al mundo bipolar, México, Senado de la República, 1991.

Trevizo, Dolores

Rural Protest and the Making of Democracy in Mexico, 19682000, University Park, Pennsylvania State University Press, 2011 . 


\section{United States, Department of State}

"Current Communist Strategy in Non-industrialized Countries”, en Problems of Communism, Iv: 5 (sep.-oct. 1955).

URQUIDI, Víctor L.

Otro siglo perdido. Las políticas de desarrollo en América Latina (1930-2005), México, El Colegio de México, Fondo de Cultura Económica, 2005.

VeGA, Mercedes de (coord.)

Historia de las relaciones internacionales de México, 18212010: Caribe, México, Secretaría de Relaciones Exteriores, Dirección General del Acervo Histórico Diplomático, 2011.

Vernon, Raymond

The Dilemma of Mexico's Development: The Roles of the Private and Public Sectors, Cambridge, Harvard University Press, 1963.

WALKER, Louise E.

Waking from the Dream. Mexico's Middle Class after 1968, Stanford, Stanford University Press, 2013.

Westad, Odd Arne

The global Cold War: third world interventions and the making of our times, Cambridge, Nueva York, Cambridge University Press, 2005.

Zuвок, Vladislav M.

A Failed Empire: The Soviet Union in the Cold War from Stalin to Gorbachev, Chapel Hill, University of North Carolina Press, 2007. 


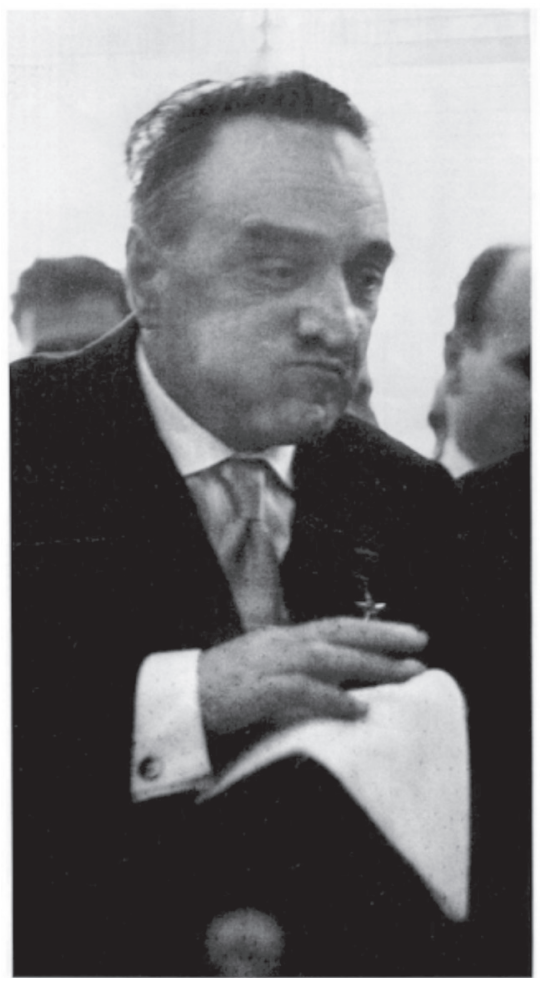

Anastás Mikoyán disfrutando de forma aparatosa un taco durante su visita a México. Revista Life (7 dic. 1959). 